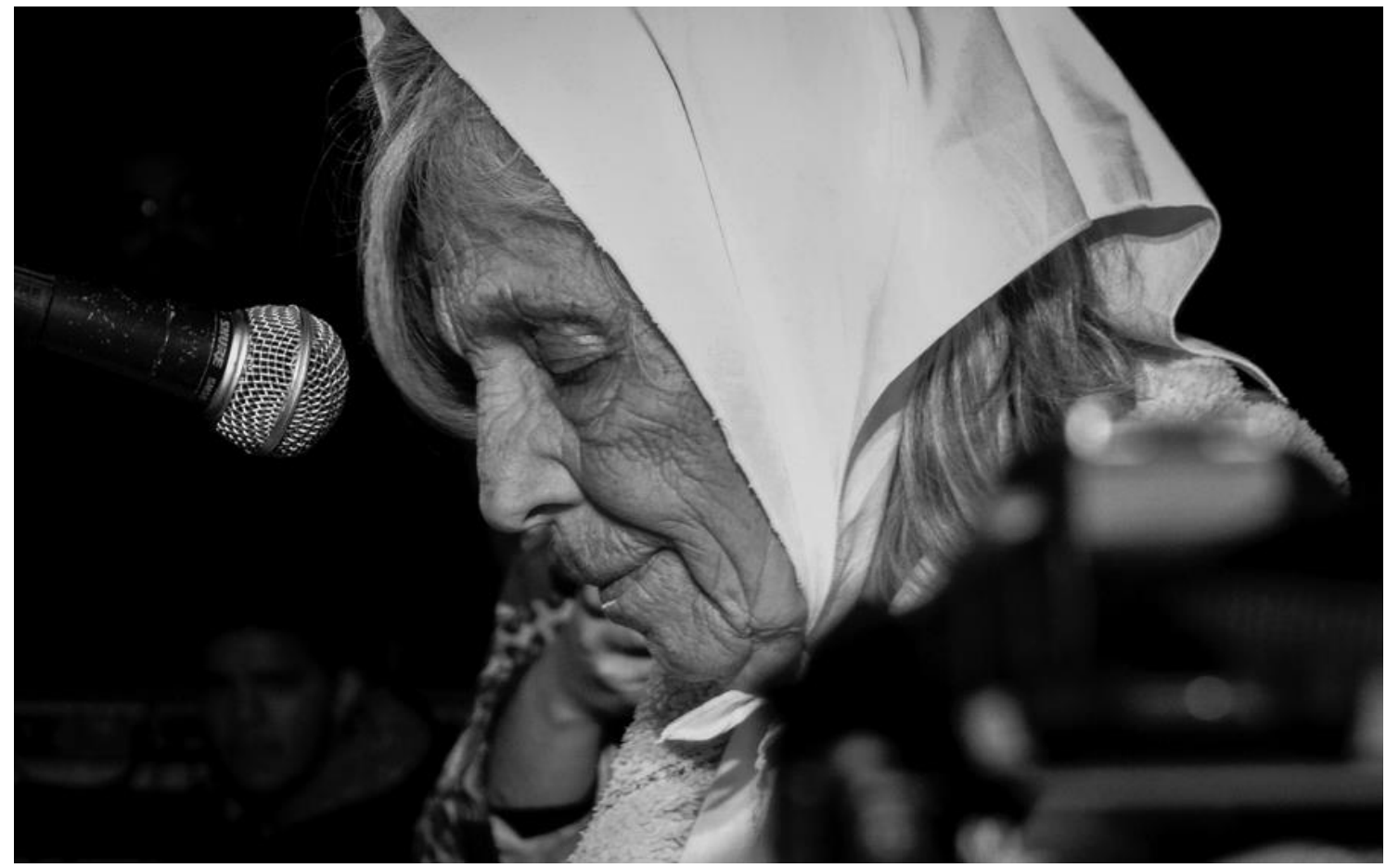

FOTOS: Irina Morán - Revista Alfilo - Periodista Feminista. Militante de Ni Una Menos Córdoba y Mujeres por un parto Respetado 


\title{
MULHERES, SABERES E COMUNIDADE: OUTRA EPISTEMOLOGIA
}

\author{
Rita Fraga Machado ${ }^{1}$
}

Resumo: Nestes ritos iniciais, apresentarei a reflexão a que se propõe este texto em três grandes eixos e, ao final, tentar uma síntese dos mesmos. O objetivo desse texto é traçar uma linha histórica epistemológica no intuito de mostrar que essa não permite a produção significativa para outras epistemologias no trabalho com mulheres da floresta. O primeiro tópico do texto tem a ver com o conceito Clássico de Epistemologia e de como, ao conhecê-lo, podemos refutá-lo com o intuito de reinventá-lo, de acordo com Paulo Freire. O segundo tópico discute acerca desses outros conceitos e dessa outra epistemologia, baseando-se na dialética, método que, ainda hoje, os filósofos da ciência insistem em dizer que não produz conhecimento. Já o terceiro momento trata-se de como essas outras epistemologias se articulam com a educação para autonomia das mulheres da Floresta como modo de vida comunitário. O objetivo é gerar novas sínteses epistemológicas como forma de produção de conhecimentos tendo as mulheres como protagonistas desse processo.

Palavras Chave: Mulheres, Epistemologia. Dialética. Comunidade.

\section{WOMEN, DIALECTICS AND COMMUNITY: ANOTHER EPISTEMOLOGY}

\begin{abstract}
In these initial rites, I will present the reflection to which this text is proposed in three main lines to try to synthesise them at the end. The purpose of this text is to delineate a historical epistemological line which the intention is to demonstrate that it does not allow significant production to other epistemologies. The text first topic is about the classical epistemology concept and how, by knowing, we can refute it with the intention of reinventing the concept, according to Paulo Freire. The second topic discuss about these other concepts and this other kind of epistemology, based on dialectic: a method that science philosophers, even today, insist on saying that it does not produces knowledge. The third moment dicuss how these other epistemologies are articulated with the education for the women' Forest autonomy as a community way of life. The final objective is generate new epistemological syntheses as knowledge method production.
\end{abstract}

Keywords: Women, Epistemology. Dialetic. Community.

\section{SOBRE O CONCEITO CLÁSSICO DE EPISTEMOLOGIA}

Algumas linhas sobre o conceito de Epistemologia.

Segundo Mário Bunge (2004, p. 586), uma Epistemologia é útil se satisfaz às seguintes condições:

- Refere-se à ciência propriamente dita;

- Ocupa-se de problemas filosóficos que se apresentam no curso da investigação científica ou na reflexão sobre os problemas, métodos e teorias da ciência;

- Propõe soluções claras e objetivas para tais problemas, soluções consistentes

${ }^{1}$ Professora Adjunta na Universidade do Estado do Amazonas - UEA. Pós-Doutoranda Programa de Pós-graduação em Educação da Universidade do Vale do Rio dos Sinos - Bolsista PNPD/CAPES. Doutora em Educação pelo Programa de Pós-graduação em Educação da Universidade Federal do Rio Grande do Sul - UFRGS na linha de pesquisa Trabalho, Movimentos Sociais e Educação. Onde foi professora substituta entre 2010-2012. Mestre em Educação pela Universidade Federal do Rio Grande do Sul. Especialista em Metodologia do Ensino de Filosofia pela UNISINOS. É licenciada e Bacharel em Filosofia pela Universidade do Vale do Rio dos Sinos - UNISINOS, Bacharel em Antropologia Social Latino Americana pela UNISINOS. Tem experiência no ensino superior, pesquisa e extensão. Seus interesses de pesquisa atualmente compreende a problemática das Mulheres e Trabalho, Movimentos Sociais Populares de Mulheres, Feminismo e Economia Feminista. 
em teorias rigorosas e inteligíveis, adequadas à realidade da investigação científica;

- É capaz de distinguir a ciência autêntica da pseudociência;

- É capaz de criticar programas e mesmo resultados errôneos, como conseguir novos enfoques promissores.

Ainda, segundo Bunge (2004, p. 587), o Epistemológico pode dar contribuições dos seguintes tipos:

- Traz à tona os pressupostos filosóficos (em particular semânticos, gnosiológicos (e)ontológicos) de planos, métodos ou resultados de investigação científicas de atualidade;

- Elucida e sistematiza conceitos filosóficos, empregados em diversas ciências;

- Ajuda a resolver problemas científico-filosóficos, tais como o de saber se a vida se distingue pela teleonomia e a psique pela inespacialidade;

- Reconstrói teorias científicas de maneira axiomática, põe a descoberto seus pressupostos filosóficos;

- Participa das discussões sobre a natureza e o valor da ciência pura e aplicada, ajudando a esclarecer as idéias a respeito;

- Serve de modelo a outros ramos da filosofia, particularmente a ontologia e a ética.

A Epistemologia é, nos termos, definida por muitos pensadores ao longo dos séculos até a atualidade. $\mathrm{O}$ termo epistemologia se refere ao estudo sobre a produção do conhecimento. Quando se menciona, no entanto, a epistemologia das ciências, se está abordando os pensadores que se preocuparam em investigar como se constrói um conhecimento de natureza científica.

A Epistemologia e a Arché, ver princípio, significa o acesso às verdades essenciais de ordem metafísica, intelectual e moral.

PRINCÍPIO (gr. apxn; lat. Principium; in.Principle; fr. Principe; al.Prinzip, Grundsatz; it. Principio). Ponto de partida e fundamento de um processo qualquer. Os dois significados, "ponto de partida" e "fundamento" ou "causa", estão estreitamente ligados na noção desse termo, que foi introduzido em filosofia por Anaximandro (Simplício, Fís., 24,31); a ele recorria Platão com frequência no sentido de causa do movimento ( $F e d ., 245 \mathrm{c}$ ) ou de fundamento da demonstração (Teet., $155 \mathrm{~d}$ ); Aristóteles foi o primeiro a enumerar completamente seus significados são os seguintes: $1^{\circ}$ ponto de partida de um movimento, p. ex., de uma linha ou de um caminho; $2^{\circ}$ o melhor ponto de partida, como p. ex. o que facilita aprender uma coisa; $3^{\circ}$ ponto de partida efetivo de uma produção, como p. ex. a quilha de um navio ou os alicerces de 
uma casa; $4^{\circ}$ causa externa de um processo ou de um movimento, como p. ex. um insulto que provoca uma briga; $5^{\circ}$ o que, com a sua decisão, determina movimentos ou mudanças, como p. ex. o governo ou as magistraturas de uma cidade; $6^{\circ}$ aquilo de que parte um processo de conhecimento, como p. ex. as premissas de uma demonstração. Aristóteles acrescenta a esta lista: "Causa" também tem os mesmo significados, pois todas as causas são princípios. O que todos os significados têm em comum é que, em todos, P. é ponto de partida do ser, do devir ou do conhecer" (Met.,V, 1, 1012 b 32-1013 a 19). (Dicionário de filosofia, 2000, p. 792)

\section{A Epistemologia pode ser entendida, ainda, segundo São Tomás de Aquino e}

Santo Agostinho:

São Tomás de Aquino ia na contramão de Santo Agostinho, colocando a razão em primeiro lugar. Tentava até mesmo explicar a fé por meios racionais, alegando que podia provar a existência de Deus. Argumentava que tudo está em movimento e todo movimento é causado por alguém; desse modo, é preciso que haja uma causa inicial, um "primeiro motor", como chamava. Além disso, constatou que é preciso que haja um Deus para que o universo esteja em tão perfeita harmonia.

\section{E por Kant e Descartes (A Razão Iluminista)}

A escolha pela filosofia de Descartes a partir de suas Meditações sustenta-se pelo fato de que tal obra se propõe a realizar uma rigorosa avaliação sobre o conhecimento das coisas do mundo. Nela, Descartes desenvolve uma perspectiva introspectiva de reflexão que inaugura um tipo de ser responsável, unicamente, em elaborar todos os processos cognitivos. Tal disposição acontece, à medida que o filósofo adota uma metodologia reflexiva fundamentada no processo de dúvida metódica. Tal atividade reflexiva consiste em duvidar de forma radical e hiperbólica de todas as coisas.

[..] Veremos, portanto, como este projeto, epistemológico, consolida a crença do ser como um eu que enquanto substancia dividida entre res cogitans e res extensa, atua no mundo também de forma dividida. Esta substancia pensante, dotada de mente e corpo é capaz de tornar toda obscuridade oriunda das percepções sensíveis em ideias claras e distintas. Assim, pouco a pouco no desenvolvimento de seu projeto, Descartes converte as razões de duvidar de todas as coisas em crenças na falsidade de todas as coisas. Assim, observamos, como a sólida crença sobre esta falsidade das coisas no mundo, estabeleceu um paradigma de interpretação da realidade que, limita o existir no mundo às ideias e representações que o ser possui do mesmo. (ANDRADE, 2009, p. 133134)

Para a crítica marxista, o sistema kantiano representa a expressão de uma fase bem definida do pensamento ocidental. O racionalismo Iluminista de Kant mostra, assim pensam Adorno/Horkheimer, "a insuficiência e a eterna limitação" do pensamento. Este não consegue penetrar no "ser", não conhece nada de novo, pois o pensamento já reproduz aquilo que a razão colocou no objeto. Daí porque Adorno/Horkheimer afirmam que "sujeito e objeto tornamse ambos nulos" em Kant. O sujeito é um substrato da racionalidade. Kant, então, prepara a "submissão de todo ente ao formalismo lógico".

Nesse sentido, a filosofia kantiana já traria uma submissão do pensar que, posteriormente, terá seu desfecho no positivismo. Aqui, o pensar se conforma ao "imediatamente dado". Adorno/Horkheimer percebem que em Kant o poder da razão contém algo de ilusório; ontologicamente é o "imediatamente dado" 
que prevalece sobre a razão. É neste ponto, como podemos notar que Kant se assemelha ao conjunto da filosofia dos Iluministas: ela não deixa de estar associada à "essência da ordem existente". Em Kant o novo é banido - e com ele, também, a "esperança" - sendo que uma nova etapa (o além) deve estar predeterminada para que possa ser pensada. Estar e não-estar no mundo; a salvação do "sujeito transcendental" como resguardo do que é humano. (MANIERI, 2011, p. 1-2)

\section{A Epistemologia pode ser entendida, ainda, sob a perspectiva de Hegel:}

Hegel inclui no seu próprio sistema a contradição, se distanciando da epistemologia tradicional na qual tese e antítese se opõem. Para Hegel, esquece-se que no processo do conhecimento embutido na tese e na antítese o conhecimento delas não é perdido. A nova fase inclui aquelas fases (tese e antítese). A síntese abrange as duas, alarga o conhecimento. $\mathrm{O}$ absoluto, para ser absoluto tem que se manifestar, senão é mera abstração. A epistemologia para Hegel é antes de tudo um exame da nossa consciência na medida em que nos relacionamos com os objetos, muito embora não possamos entender muito bem esta relação, podemos entender o objeto na medida em que ele é algo para a nossa consciência. (COSTA, 2005, p. 185)

Sobre a Epistemologia, Karl Marx entende a partir de Hegel:

A estrutura dialética de Marx é sustentada em Hegel, portanto é necessário destacarmos que Marx não é Hegeliano, porém, é impensável sem o mesmo - o edifício marxiano é construído sobre a arquitetura hegeliana. Conflito nesse contexto deve ser entendido como argumentação, diálogos entre as teorias, debate acadêmico científico. Marx parte da premissa hegeliana de uma filosofia dialética que se limita ao mundo dos espíritos, mesmo destacando os aspectos do movimento. Porém Marx modifica a ótica dialética, tornando-a real, material. "A dialética não é um movimento espiritual que se opera no interior do entendimento humano" (GADOTTI, 1997, p.21). Marx de fato trabalha a dialética materialista. (LIMA, 2017, p. 1037-1038)

\section{Já Piaget é quem desenvolve o que ficou conhecido como a Epistemologia}

\section{Genética:}

[...] epistemologia que é naturalista sem ser positivista, que põe em evidência a atividade do sujeito sem ser idealista, que se apoia também no objeto sem deixar de considerá-lo como um limite (existente, portanto, independentemente de nós, mas jamais completamente atingido) e que, sobretudo, vê no conhecimento uma elaboração contínua: é este último aspecto da epistemologia genética que suscita mais problemas e são estes que se pretende equacionar bem assim como discutir exaustivamente. (PIAGET, 1971, p. 11)

Sobre a Epistemologia Histórica de Bachelard,

Bachelard dizia constantemente, em seus cursos na Sorbonne, que a 
epistemologia consistia, no fundo, na história da ciência como ela deveria ser feita. Ele queria dizer com isso que toda reflexão efetiva, capaz de estabelecer o verdadeiro estatuto das ciências formais ou abstratas (lógica e matemática) e das ciências empíricas (ciências naturais e sociais), deve ser necessariamente histórica. Bachelard alicerçou a sua epistemologia numa epistemologia nãocartesiana, que rejeita a asserção de Descartes (1596-1650), segundo a qual o conhecimento deve estar baseado em intuições das primeiras verdades firmemente estabelecidas. No entender de Bachelard, todas as afirmações do conhecimento estão sujeitas a revisão à luz de evidências posteriores. (FILHO, 2010, p. 2)

\title{
Na Epistemologia Arqueológica de Foucault:
}

Note-se a sutil complementação entre escrever uma história "do espaço de constituição" do pensamento como uma história da verdade. Seguindo tal indicação, podemos inicialmente dizer que por arqueologia devemos compreender uma investigação histórica sobre condições de possibilidade que, tal como matrizes do saber, possibilitam o desenvolvimento de diferentes formas de discurso com pretensão à veracidade. Espaço dinâmico e relacional que Foucault denomina - já ao final da década de 70 - de "jogos de verdade." Trata-se, portanto, de uma investigação de cunho aparentemente epistemológica. Distante, porém, das tradicionais teorias do conhecimento que têm como objetivo instaurar um fundamento, a investigação arqueológica define-se por outra orientação. Não se trata de fundar a ciência e a objetividade desvelando as condições últimas do conhecimento positivo. A arqueologia se coloca na exterioridade do discurso científico, respeitando sua autonomia. (GIMBO, 2017, p. 100)

\section{Sobre a Epistemologia Racionalista Crítica de Popper sabe-se que:}

A filosofia das Ciências de Popper consiste na verificação de valor da teorias cientificas através do princípio da verificação e da falsificação. Para Popper, todas a leias e teorias científicas são, em sua essência, hipotéticas e conjecturais. As teorias cientificas são como livres criações de nosso espírito. Aquilo que procuramos nas ciências é um elevado conteúdo de informação, a busca de uma probabilidade, através da refutabilidade. (TESSER, 1995, p. 95)

\section{A Epistemologia Crítica de Habermas funda-se em:}

\begin{abstract}
A Epistemologia crítica tem por objetivo essencial interrogar-se sobre a responsabilidade social dos cientistas e dos técnicos. O que a epistemologia crítica pretende mostrar é que a verdadeira significação da ciência não reside mais no saber enquanto tal, mas no poder que ele efetivamente confere (ciência-tecnologia-indústria). Um gigantesco processo de produção racionalizado e industrializado. (TESSER, 1995, p. 95)
\end{abstract}

\section{Já a Epistemologia do Sul}

Trata-se do conjunto de intervenções epistemológicas que denunciam a supressão dos saberes levada a cabo, ao longo dos últimos séculos, pela norma epistemológica dominante, valorizam os saberes que resistiram com êxito e as reflexões que estes têm produzido e investigam as condições de um diálogo horizontal entre conhecimentos. A esse diálogo entre saberes chamamos 
ecologias de saberes (SANTOS; MENESES, 2010, p. 7).

Como a Epistemologia exerce seu papel de reflexão e crítica, compreendemos que essas epistemologias, até agora desenvolvidas e acima expostas, não deram conta de compreender de maneira emancipadora a forma que entendemos a produção de conhecimento (aquela que alarga consciências coletivas) das experiências latinoamericanas, principalmente as do norte do país.

\section{A PERSPECTIVA DIALÉTICA COMO ALTERNATIVA A EPISTEMOLOGIA CLÁSSICA POSITIVISTA}

Em artigo recente, Ferraro (2015) tratou das principais correntes dentro do positivismo, desde o utópico revolucionário de Condorcet, no final do século XVIII, passando pelo utópico socialista de Saint-Simon, o da ordem ou conservador de Comte, até o utilitarista de Stuart Mill e de Spencer, sociológico de Durkheim, no século XIX, para chegar ao de Popper, em pleno século XX.

Löwy (1985) resume o positivismo em três ideias fundamentais: a sociedade humana é regulada por leis naturais; os métodos e procedimentos para conhecer a sociedade são exatamente os mesmos utilizados para conhecer a natureza; as ciências sociais devem funcionar exatamente segundo o modelo de objetividade científica das ciências naturais, isto é, como ciências objetivas, neutras, livres de juízos de valor, de ideologias políticas, sociais e outras.

O mesmo autor acrescenta que as propostas metodológicas que levam o nome de multidisciplinaridade, interdisciplinaridade e transdisciplinaridade radicam no positivismo, não sendo mais que tentativas de resolver problemas teóricometodológicos que emergiram da própria concepção e prática do positivismo.

Já o termo dialética é plurissignificativo. Na Grécia antiga (Sócrates), dialética era a arte do diálogo. Aproximam-se desse sentido os termos "dialogicidade" e “diálogo”, presentes na obra Pedagogia do oprimido (1979), de Paulo Freire:

\footnotetext{
Na acepção moderna, porém, dialética é, como diz Konder (1998, p. 88), “o modo de pensarmos as contradições da realidade, o modo de compreendermos a realidade como essencialmente contraditória e em permanente transformação". É o que se tem na dialética desenvolvida por Marx, com vistas à sua aplicação na crítica da economia política clássica (Adam Smith, David Ricardo...) e do socialismo utópico (Saint-Simon, Fourier e Owen...). Note-se que esse segundo sentido de dialética, marxiano, também está presente na obra
} 
de Freire, como, por exemplo, no entendimento do analfabetismo como injustiça social, como se viu logo no início. (FERRARO, 2018, p. 99)

Ferraro (2018) aponta que Calvez ensina que a questão do método é o problema central do pensamento de Marx. Foi, no confronto com Hegel e com os hegelianos, que Marx teve que tomar posição sobre método, de maneira que a dialética se situa no coração do seu pensamento. Daí a necessidade de "examiná-la [a dialética] neste lugar central e mostrar como ela pretende constituir o fundamento do real, do saber e do dever ou da ética" (CALVEZ, 1956, p. 336-337. Grifos do autor). Note-se que, assim entendida, a dialética tem a ver não só com a produção de conhecimento sobre a realidade, mas também com essa mesma realidade e com a práxis de transformação da realidade estudada, na qual a educação ocupa lugar importante.

\begin{abstract}
Em texto de 1859, Engels (s. d., vol. 1, p. 304-312) diz que Marx e ele se haviam defrontado com o problema de saber com que método tratar a ciência e que havia apenas duas alternativas: a dialética hegeliana, sob a forma completamente abstrata, especulativa, em que a deixara Hegel, e o método ordinário, wolfiano, que voltava à moda, "do qual se serviam também os economistas burgueses para escrever seus livros volumosos e incoerentes". o autor diz também que ele e Marx optaram pelo método hegeliano pelo "formidável sentido histórico" que o animava, e porque toda a filosofia hegeliana "nutria-se, não obstante, do conteúdo real" e, ainda, que a crítica do método hegeliano se constituiu num desafio para eles, e que Marx era a única pessoa que podia retirar da lógica hegeliana a medula das descobertas de Hegel e restaurar o método dialético, despojado da sua roupagem idealista, e aplicá-lo na crítica da economia política. (FERRARO, 2018, p. 98)
\end{abstract}

Ferraro (2018) destaca que, em carta a Kugelmann, de 6 de março de 1868, Marx (1997) dizia que Herr Dühring sabia muito bem que seu método não era hegeliano, uma vez que ele, Marx, era materialista, e Hegel, idealista. No entanto, essa diferença não o impedia de reconhecer a importância da dialética hegeliana, desde que purificada de sua forma mística: "A dialética de Hegel é a forma básica de toda a dialética, mas somente depois que ela foi extirpada de sua forma mística, e isto é precisamente o que distingue meu método.” (MARX, 1997, p. 229).

Se a dialética hegeliana se dava no mundo das ideias, a dialética marxista situava-se no mundo real, material, onde tem lugar o trabalho humano como mediador entre o ser humano e a natureza na produção dos meios de vida, como se tem no livro 1 de $O$ capital:

Antes de tudo, o trabalho é um processo de que participam o homem e a natureza, processo em que o ser humano, com sua própria ação, impulsiona, regula e controla seu intercâmbio material com a natureza. Defronta-se com a 
natureza como uma de suas forças. Põem em movimento as forças naturais de seu corpo - braços, pernas, cabeça e mãos -, a fim de apropriar-se dos recursos da natureza, imprimindo-lhes forma útil à vida humana. (MARX, 2018, p. 118)

\section{OUTRA EPISTEMOLOGIA SOB BASES DIALÉTICAS}

A toupeira, animal com problemas de visão, circula embaixo da terra sem fazer alarde e surge onde menos se espera: "tal imagem remete às incessantes contradições intrínsecas do capitalismo, que não deixam de operar, mesmo quando a 'paz social' - a das baionetas, a dos cemitérios ou a da alienação - parece prevalecer”. (SADER, 2009, p. 7). Mas, quando a toupeira sai do buraco, volta a enxergar outras coisas até então invisíveis a ela. É também o registro da esperança que, assim como a toupeira, sem fazer alarde, surge do fundo da terra, fazendo que a América Latina desponte no horizonte futuro em que "outro mundo é possível”. (SADER, 2009)

No caso das Mulheres da Floresta, são as relações de conhecimento pautadas pelo saber tradicional, acerca da floresta e da água. Nas comunidades tradicionais da Amazônia, as re (existências), as ações do cotidiano, o trabalho e as relações sociais são cheias ou imbricadas de sentidos que envolvem mitos, ethos e histórias. Partindo dessas particularidades, a pesquisa que estamos realizando desde 2012, ano em que cheguei a Tefé (Médio Solimões), nos aponta para a existência de outra epistemologia.

Durante essa caminhada de pesquisa e reflexão no interior do Amazonas, fui percebendo que o termo comunidade ocupa um lugar central. Quase tudo na vida da floresta se constrói por meio das comunidades e de forma comunitária, inclusive o processo de participação das mulheres na vida comunitária, ou seja, na escola, na horta, nas reuniões, na igreja. $\mathrm{O}$ comum $^{2}$ é um modo de vida dessas populações, ou seja, o bem comum. A Comunidade não é um corpo ou um objeto, mas uma construção ideológica que se baseia na necessidade singular da segurança, do conforto, da familiaridade e do sentimento de pertencimento de que fazemos parte de algo maior que nossa individualidade, da delimitação do "nós" (o familiar) e dos "outros" (o estranho), sem perder a conexão com a coletividade (totalidade). (BAUMAN, 2003)

As identidades se reinventam num fazer-se e viver-se coletivo. Tudo parece assumir outro sentido para os sujeitos que ali pertencem. As individualidades estão ali, recheadas de práticas comuns. Uma unidade que expressa um núcleo único e revelador

${ }^{2}$ Comum aqui significa o que é de todos, mesmo que um tenha adquirido. Aqui, o uso qualitativo do tempo, na forma comunal de intercâmbio reprodutivo, representa o nível historicamente atingível e, nas fases mais avançadas do socialismo, o único e absoluto modo de mediação dos produtores associados. (MESZASROS, 2009) 
de modos de vida. Diante de tanta precariedade da existência, as estratégicas passam pela solidariedade e pela união das pessoas. Um núcleo estável que "ocupa de las ambivalências actuales do individualismo moderno, signado pela la tension mencionada entre segurid e liberdad" (CARILLHO, 2014, p. 93).

A liberdade, aqui, significa que todas as pessoas poderão desfrutar do bem. Esta liberdade contrapõe-se à liberdade de mercado, aquela que traz um imaginário falso de conquista e segurança. Na comunidade, a segurança é real e a liberdade é o que dá sentido às ações. A atividade dos seres não aparecerem dissociadas da sua natureza, os sujeitos encontram-se numa sociedade natural em que a cisão de interesses não aparece na produção do bem comum. Há o que chamamos de identidades, as quais não se individualizam na atividade total realizada por eles. Esta atividade está divida voluntariamente, o que converge para um poder comunitário, dominado pelos próprios comunitários. Afirmamos que há uma realização plena, que não expropria trabalho nem riqueza. E tais constatações requerem que olhemos para esses dispositivos numa nova distinção social.

Para Redfiel, la comunidad requiere ser distintiva con relación a otros grupos humanos, pequeña, como para que todos sus miembros estén a la vista uno con otros, y autosificiente: una comunidad esos rasgos, una comunidad no se siente convocada por la reflexion, la crítica o la innovación. (CAMILO, 2014, p. 92)

A interferência do mundo exterior provoca muitas ambiguidades existenciais, e a escola é o maior canal dessa interferência. São diferentes formas de vida que tentam ser introduzidas pela sociedade contemporânea. A interferência desse mundo exterior é muito forte, mas há o que se chama de resistência. Essa resistência significa a continuidade de luta por escola específica às suas realidades, à saúde (ausente nas comunidades) e o resistir a essa lógica perversa capitalista da destruição da natureza. Esta convida os comunitários, o tempo todo, a refletirem, conduzindo-os para que todos possam ter um mesmo entendimento do que essas resistências significam na sua vida comum, sem perder suas individualizações, como valores, normas, jeitos, alimentação, sagrado, vestimenta etc.

Dessa forma, concordamos com Agamben (2013) sobre a idéia de que, sem a individualização, não é possível pensar o singular e, por sua vez, o comum, de forma dialética. 
exemplo a humanidade) não de uma forma ou essência ou propriedade, mas de uma ultima realitas, de uma 'ultimidade' da própria forma. A singularidade não acrescenta nada a forma comum. (...) não se oponha a ser colocada como uma unidade singular qualquer que seja" (AGAMBEN, 2013,p, 25).

O ter-lugar, o comunicar das singularidades no atributo da extensão, não as une na essência, mas as dispersa na existência.

(AGAMBEN, 2013, p. 25)

Para Agamben (2013, p. 27), "seria a in-diferença com respeito às propriedades é o que individua e dissemina as singularidades, as torna amáveis (quodlibertais)". Essa da natureza, do comum. Do mesmo modo, o rosto humano não é nem o um individualizar-se de uma face genérica nem o universalizar-se de traços singulares: é rosto qualquer, no qual o que pertence à natureza comum e o que lhe é próprio são absolutamente indiferentes.

Bauman (2003) em seu livro Comunidade a busca por segurança no mundo atual, faz uma observação sobre os conceitos teóricos e clássicos acerca da comunidade, de forma geral, para, então, entrar na reflexão das comunidades hoje existentes. Sentimos falta, nessas reflexões, das comunidades reais da Amazônia, tendo em vista que, nesse território, encontramos a forma mais antiga de viver em comunidade. Enfim, como todo intelectual contextualiza suas análises, compreendemos de qual lugar fala Bauman. Ou seja, "a comunidade de entendimento comum, mesmo se alcançada, permanecerá, portanto frágil e vulnerável, precisamos para sempre de vigilância, reforço e defesa”. (BAUMAN, 2003, p. 19).

A promoção da segurança, segundo o autor, sempre requer o sacrifício da liberdade, enquanto esta só pode ser ampliada à custa da segurança. Mas a segurança sem liberdade é o que equivale à escravidão (e, além disso, sem uma injeção de liberdade, acaba por ser, afinal, um tipo muito inseguro de segurança); e a liberdade sem segurança equivale a estar perdido e abandonado (e, no limite, sem uma injeção de segurança, acaba por ser uma liberdade muito pouco livre). Essa circunstância provoca, nos filósofos, uma dor de cabeça sem cura reconhecida. Ela também torna a vida em comum um conflito sem fim, pois a segurança sacrificada em nome da liberdade tende a ser segurança dos outros, e liberdade sacrificada em nome da segurança tende a ser liberdade dos outros. (BAUMAN, 2003, p. 24)

\section{AS EPISTEMOLOGIAS EM SÍNTESE: MULHERES E FLORESTA}

Esses desafios nos incentivaram a levantar questões contraditórias e de 
conhecimento acerca dos saberes tradicionais, os quais, dificilmente, aparecem nas estatísticas e nas epistemologias elaboradas pelas instituições de ensino. Elas estão enfrentando, diariamente, violências de várias formas, trabalhando e "pegando duro" no sol e na roça, cuidando da floresta e preservando os rios, a mata, os animais e sua comunidade. A busca pelo bem comum e autonomia é algo estruturante na vida das comunidades "(...) a busca daquilo que propicia a boa convivência que inclui as pessoas se impõem (...) estamos defendendo florestas e rios, povos primitivos, e as mulheres da floresta. Estamos abrindo espaços, para novas formas de justiça e direito das mulheres". (GEBARA, 2016 p. 198)

A educação Popular parece se alargar para além de nossos limites geográficos. O povo é bem mais que o meu povo, o mundo mais do que minha cidade, a casa comum mais do que a minha casa. Há algo de ilimitado que se descortina, de mais amplo, de maior do que meu pequeno universo e minhas reivindicações embora elas guardem sua importância e seu valor. A solidariedade alarga a sua tenda. (GEBARA, 2016, p. 198)

Entendemos que há um sentimento em todas: o de reinventar as relações na comunidade. Uma "aventura do comum", como diz Gebara. Há um sentimento comum de que necessitamos reinventar e escrever essas epistemologias (nós intelectuais comprometidos com a classe). Não sei se estamos reinventando a humanidade ou se somos capazes disso, dado o alto grau destrutivo do capital em relação aos bens comuns. Harribey (2014, p. 21) explica que “[...] o valor do estoque de recursos naturais é inestimável em termos econômicos [...], uma vez que tais recursos condicionam a vida da espécie humana". Isso significa que os recursos naturais não podem ser reduzidos a uma categoria econômica. Sem a natureza, os seres humanos não podem produzir nada, nem em termos físicos, nem em termos de valor econômico. A atividade econômica insere-se, necessariamente, em relações sociais e numa biosfera. Não se pode dispensar a natureza para produzir coletivamente valor de uso, e não se pode substituí-la indefinidamente por artefatos. Nesse sentido, a comunidade apresenta-se:

\footnotetext{
"pertencer a uma comunidade significa renegar parte de nossa individualidade em nome de uma estrutura montada para satisfazer nossas necessidades de intimidade e da construção de uma "identidade".

(ZYGMUND BAUMAN, 2003, p.123)
}

Sobre o debate atual acerca de comunidades, temos:

Este "sintonia comunitário", em SUS múltiples expresiones sociales, culturales e políticas, convocó desde la década de los ochentas del siglo XX a diferentes pensadores y estudiosos de la sociedade de países metropolitanos. En primeiro 


\begin{abstract}
lugar, como ya se dijo, en el mundo acadêmico anglosajón comezó el debate entre filósofos liberales e comunitarista, cuya preocupacion e debate era defender la melhor maneira como a democracias republicanas podiam abordad y direcionar as co existências dentro de las sociedades de diferentes grupos humanos con tradiciones, modos de vida e cosmovisonaes diversas. Esa cuestión convocó a importante pensadores norte americanos y europeus como Rawl (1979, 1986 y 1996), Walzer (1983), Taylor (1993), Dworkin (1996), Rorty (1992), Etzioni (2001), Thiebaut (1992) y Camps (1993). (CARRILHO, 2014, p. 23)
\end{abstract}

Ao longo da investigação, foi-se percebendo, por meio da metodologia de pesquisa, que existem outras formas de produção de conhecimento que chamamos de epistemologias em síntese - essa produção se caracteriza como sendo comunitária. Nesse sentido, toda a comunidade se organiza em torno de um único objetivo: a qualidade de vida e o bem viver, os quais passam pela ação coletiva de preservação e conservação do meio onde estão inseridos, passam pelo retomada dos saberes tradicionais e a valorização dos mesmos.

\title{
REFERÊNCIAS
}

ABBAGNANO, Nicola. Dicionário de filosofia. Tradução da $1^{\circ}$ edição brasileira coordenada e revista por Alfredo Bosi; revisão da tradução e tradução de novos textos Ivone Castilho Benedetti - $4^{\circ}$ ed. - São Paulo: Martins Fontes, 2000.

AGAMBEN, Giorgio. A comunidade que vem. Tradução e notas Claúdio Oliveira. Belo Horizonte: Autêntica Editora, 2013.

ANDRADE, Eloísa de Benvenutti. O projeto epistemológico cartesiano. Kínesis, Vol. I, nº 01, Março-2009, p.133-149

BAUMAN, Zygmunt. Comunidade: a busca por segurança no mundo atual. Rio de Janeiro: Jorge Zahar Ed., 2003.

BUNGE, Mario. Una caricatura de la ciencia: la novisima sociologia de la ciencia. Interciencia, Caracas. v.16, n. 2, p. 69-77, abr. 1991. Disponível em: https://www.interciencia.net/\#top. Acesso em: 08 mai. 2018.

CARRILHO, Afonso T. El retorno a La comunidad: problemas, debates y desafios de vivir juntos. Fundação centro deducação y Desarrollo Humano - CINDE. Editora El Búho Ltda, 2014.

GÓES, Lara Denise. A Dialética e circularidade da lógica de Hegel na filosofia de Charles Taylor. Ítaca. n. 29, p. 183 - 198, jul. 2016. Disponível em: https://revistas.ufrj.br/index.php/Itaca/article/view/3498/2685. Acesso em: 08 mai. 2018 .

FERRARO, A. R. Epistemologia da agroecologia: dialética versus positivismo. 
Desenvolv. e Meio Ambiente. v. 34, p. 117-134, ago. 2015.

FERRARO, Alceu. Educação popular como ato político. Rita de Cássia Fraga Machado; Fernando Bilhalva Vitória (Orgs.). São Leopoldo: Karywa, 2018. p. 94.120.

GEBARA. I. Educação popular: a ressignificação das expressões In: Estudos feministas, mulheres e educação popular. Amanda Motta Castro, Rita de Cássia Fraga Machado (organizadoras). Curitiba: CRV, 2016. p. 198-208.

GIMBO, Fernando. Epistemologia e arqueologia: Foucault e a história da ciência francesa. Kínesis. Vol. 4, n.20, p. 99-125. Jul. 2017.

GIMBO, Fernando. A Epistemologia Genética. Rio de janeiro: Vozes, 1971.Tradução: Nathanael C. Caixeiro. L“èpistémologieGenétique. Paris: Universitaries de France, 1970 .

LIMA, Wanderson Pereira. Uma Introdução À Epistemologia Marxista Na Teoria HistóricoculturaL. Inhumas: UEG, p. 1036-1044, 2017.

MANIERI, Dagmar. O Transcendental em Kant (1984-9052). Theoria. Pouso Alegre: v. 03, p. 1-17, 2011.

MARX, K. O 18 Brumário e Cartas a Kugelmann. 6 ed. Rio de Janeiro: Paz e Terra,. 1997.

Mészáros, I. Para além do capital: rumo a uma teoria da transição. São Paulo: Boitempo, p.1102, 2009.

SADER, Emir. Nova Toupeira, os Caminhos da Esquerda Latino-americana. São Paulo: Boitempo, 2009.

SANTOS, B. S.; MENESES, M. P. (Org.). Epistemologias do Sul. São Paulo: Cortez, p. $637,2010$.

SCOFOnO, G. R. Santo Agostinho X São Tomás de Aquino: contribuições do cristianismo para a filosofia. Disponível em: https://ufrj.br/noticia/2015/10/22/santoagostinho-X-s-o-tom-s-de-aquino-contribui-es-do-cristianismo-para-filosofia. Acesso: em 08 mai. 2018.

SILVEIRA, Fernando Lang. A teoria do conhecimento de kant: o idealismo transcendental. Instituto de Física UFRGS. Porto Alegre: Editora Springer, 28 v. 19, p. 28-51, mar. 2002.

TESSER, Gelson João. Principais linhas epistemológicas contemporâneas. Educar. Curitiba: Editora UFPR. n. 10, p.91-98, ano 1999. 